\title{
Making sense of experience in preschool: Children's encounters with numeracy and literacy through inquiry
}

\begin{abstract}
Opening up space for authentic inquiry in preschool can influence the extent to which children can make use of their growing mathematical and linguistic understandings to make sense of themselves and the world around them. Authentic inquiry here refers to investigation that arises naturally from the interests and questions of the children as they experience the learning environment. Three authentic examples are presented from the work of four- to five-year-old children in the domains of mathematics and literacy development to illustrate how the two domains need to be viewed as intertwined at the preschool level. Reflections are also offered on the role of the learning environment, the role of curriculum and the role of teachers and other adults in the learning process. This manuscript is based on a plenary address given in Grahamstown, South Africa at the SARAECE Research and Development week: "Strengthening Foundation Phase Education" conference at Rhodes University in September 2012.
\end{abstract}

Keywords: early years, literacy, numeracy, preschool, inquiry, sense-making, studentled, international, IB-PYP, Reggio

Marjorie Henningsen, Wellspring Learning Community, Founding Head of School, Beirut, Lebanon. Email address: marjhenningsen@gmail.com

South African Journal of Childhood Education | 2013 3(2): 41-55 | ISSN: 2223-7674 |๑ UJ
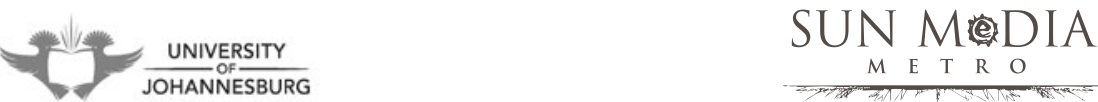


\section{Introduction}

Children's literacy and numeracy are often talked about in tandem as equally important aspects of a child's development and later success in school and in life. However, at the same time, they are still believed to be separate and distinct domains in most discussions of school curricula and in teacher education. Maintaining these boundaries in our discourse about early childhood settings may be an artefact of our adherence to traditional disciplinary boundaries in thinking about what children learn in school. We may also be tied to thinking in terms of "acquisition" of necessary skills, rather than a true reflection of how numeracy and literacy skills are actually acquired in a more blended way (Erickson, 2007). Even the act of making sense of experience and articulating one's developing ideas is related to mathematical reasoning about data. Essentially, there is a great deal of evidence that young children organise their understanding and sense making as if organising data - they generalise from experiences (Nelson, 1986). Perhaps the overly traditional academic approach to thinking about early years curriculum is an obstacle to opening up space for children's authentic inquiry in school (Gronlund, 2010).

If we want to move beyond this traditional view in order to better meet the needs and natural learning processes of children, then we need to see literacy and numeracy as more than just learning to read, write, count, and do arithmetic accurately and fluently. In the life of the developing child, literacy and numeracy have a much broader meaning. In addition to the skills of reading and writing, literacy is also the capacity to recognise, comprehend, and appreciate all the forms of communication we encounter in the world, whether it is spoken, broadcast, symbolic, textual, or digital in nature. Numeracy goes beyond counting and arithmetic to encompass the capacity to use mathematical understanding and skills to solve problems in complex social settings we encounter daily in life. Numeracy has to do with spatial sense, making sense of data, understanding patterns and sequences, and seeing where mathematics can be applied to solve a problem. Numeracy is both about quantitative thinking and being able to communicate quantitatively, thus it is naturally intertwined with literacy in the broad sense outlined above.

\section{Inquiry and emergent learning}

The consensus internationally in the field of early years education is that effective learning for young children is fundamentally grounded in how the child actively makes sense of direct experience and that this is a fundamentally social process. This notion of early learning is not new and is firmly rooted in the philosophy of John Dewey, the subsequent theoretical and experimental work of Jerome Bruner, and Lev Vygotsky, among other well-known historical scholars in the field of education. We know that natural human inquiry is an active process rather than a passive one. Human inquiry consists of doing and experimenting, seeking information, reflecting and wondering (Lindfors, 1999; Bruner, 1977). In all cases, the learner is intentionally going beyond the present and engaging with others or the work of others and so the act of inquiry 
is creative, constructive, and significant in nature. Thus, effective learning for young children is inquiry-based and meaning-centred, and essentially a social interaction (Dewey, 1916; Bruner, 1990; Lindfors, 1999; Prairie, 2005).

If we take to heart the real nature of human learning, we are challenged to think deeply about curricula and appropriate school learning environments for young children. When everything is based on prescribed activities and methods that remain relatively unchanged from year to year, the curriculum may be viewed as "things to cover" rather than as an important learning experience for children. The curriculum can become stale and unresponsive to the needs of the children as developing learners. One solution is to allow the curriculum to be developed by teachers along the way in response to the natural learning of the child and yet still with reference to expected trajectories of learning, an approach known as emergent curriculum (Stacey, 2009). An emergent approach puts the teacher at the centre of curriculum development.

Through observation, documentation, making children's thinking visible, interpretation of the documentation of learning, and active "learning with" the children, the teacher builds the learning environment and rich learning opportunities based on the interests and natural questions of the children. Teachers have to be skilful listeners, observers, and questioners. They also need to have the tools and skills for documenting what they are seeing and hearing in order to make learning visible, to reflect on it, interpret it, discuss it with others and make decisions about what might happen next in the classroom. Teachers need to be willing to inquire with children, play with them and dialogue with them in natural conversations, rather than scripted quizzing sessions aimed at seeing what children remember. Teachers also need to be able to capitalise on spontaneous opportunities that arise from daily, even routine activity, noticing possible connections to questions and interests of the children or possibilities for noticing social and other kinds of patterns in the environment. Finally, this approach also entails maintaining regular communication with children's home caregivers, providing them with ways they can open up space for inquiry outside of school or provide opportunities for children to converse, build vocabulary or practice skills at home. In the emergent approach curriculum is dynamic and engaging for children (Stacey, 1999) and also requires teachers to employ all their professional skills and knowledge of how children think and learn to create the best learning environment they can.

A well-documented and international example of using an emergent approach can be found in the practices of Reggio Emilia (Renaldi, 2006), which have been adapted and replicated in many countries. The city of Reggio Emilia in Italy is well known for its municipal education law regarding early childhood education. In Reggio the education law is framed in terms of children's rights to an education that respects their individual learning processes as well as enables them to be full participants in the social culture around them. There is an emphasis on social learning, creativity, connecting to the child's culture, and using exploration of the social, natural and built environments as catalysts for building skills and shared understanding of concepts. There is also an emphasis on choice and allowing children to make decisions about what questions 
they will pursue. Children's work is highly respected and always displayed with respect and there is an emphasis on making the thinking of the children, as well as the teachers' interpretations of what is being learned, visible to the community.

In Reggio Emilia, they describe the "Hundred Languages of Children" (Reggio Children, 2011). The "Hundred Languages" refers to the idea that children are always learning and expressing and representing their knowledge in many ways that include spoken language, but also go well beyond it. It is the adults that need to endeavour to understand and interpret children's languages. In this view, the lines between what it means for a child to become literate and to gain any particular knowledge, including mathematical understandings, are blurred. For example, if the child is reasoning about the relationship between the size of a unit and the measure of an attribute - is it mathematics or is it language?

\section{Finding common ground for developing literacy and numeracy}

What we want children to know, as organised into traditional school subjects, is not experienced naturally by children that way (as separate bodies of knowledge); however, many definitions of numeracy and literacy are still articulated in terms of disciplinary strands that we often see in reform era subject matter standards documents or sections of school curriculum frameworks or university course syllabi. The tendency to focus on literacy and numeracy as distinct sets of knowledge or skills to be acquired in early childhood education perhaps is not that useful in the early years and becomes an obstacle to rethinking the nature of the learning environment in school.

It would be hard to imagine any authentic inquiry project that can be carried out in school that would not provide a rich context for children to acquire and practice their emergent literacy and numeracy skills (Katz \& Chard, 2000). A common ground between notions of literacy and numeracy must be set in order to rethink the learning environment as a place of inquiry where both literacy and numeracy emerge together. Acknowledging the paramount importance of social inquiry as the main context for learning provides this common ground.

Mathematics and language are both tools for inquiry, communication and reasoning, and the understanding of each informs the other. Children naturally use both of them as they learn to "decode" the environment and make sense of their experience with their teachers and peers. To see this, it might be more useful to think of mathematics and language not as school subjects or disciplines, but more broadly as ways of knowing and ways of representing knowledge. Indeed, as a young child is learning how to read a measuring tape or a metre stick the child is learning to decode the meaning and organisation of the symbols contained on it. This literacy-building act of making sense is expressed in the following quotation from a four-year-old boy, Rey, describing how he is reading the metre stick to his friend: "I was here (pointing to a place on the metre stick) and I was telling Zuri if I was this much (pointing at certain numbers) and Zuri said 'Yes.' It's measurement." Rey is demonstrating his awareness, 
not only of "how to read" the metre stick, which is a cultural artefact, but also "how to use" it as a tool for a specific mathematical purpose.

Furthermore, the development of numeracy skills is greatly enhanced as children begin to represent their mathematical understandings through verbal language, modelling and written inscription. And at the same time, mathematical representation then becomes a great context for the development of literacy skills through conversation, use of descriptive language, understanding the meanings of symbols, and the development of writing (Scheinfeld, Haigh \& Scheinfeld, 2008). Particularly when children employ written representations to express their mathematical understandings resulting from inquiry, the essential relationship between numeracy and literacy is clear.

Below are three brief examples drawn from the authentic work of four- and five-year-old children at a primary school in Beirut, Lebanon. The school is a private international school that follows the Primary Years Program of the International Baccalaureate (IBO, 2009) with strong influences from the Reggio Emilia approach to early childhood education (Edwards, 2002; Reggio Children, 2011). Teachers at the school are organised into teaching pairs that function as a team for all sections of a particular level. So for example, each classroom of twenty four-year-olds have two equal-status teachers (a native or near-native speaker of English and a native speaker of Arabic) designated as homeroom teachers. However, with two sections, the team of four teachers would meet regularly together to plan for the inquiry for both sections on a weekly basis. These meetings include discussing on-going learning expectations for students with respect to disciplinary skills and concepts, trans-disciplinary skills and concepts, and the context of the inquiry. They also discuss what materials and resources or field trips will be available for students and they share observations and data about what they are seeing and hearing from students in various activities in order to interpret learning and to keep things progressing. During inquiry time, it is common for children to mix across sections so that resources and facilities can be shared across sections in ways that differentiate more closely to the specific needs of each child. The examples given below are intended to illustrate the tight relationship between numeracy and literacy development in the school-based learning experiences of very young children engaged in inquiry.

\section{Requesting a new Doormat: Measuring for a Purpose}

Four-year-old children write a letter to the school administration with a diagram and detailing the dimensions of a new doormat they want for their classroom measured in glue stick lengths. Is this about numeracy or literacy? 


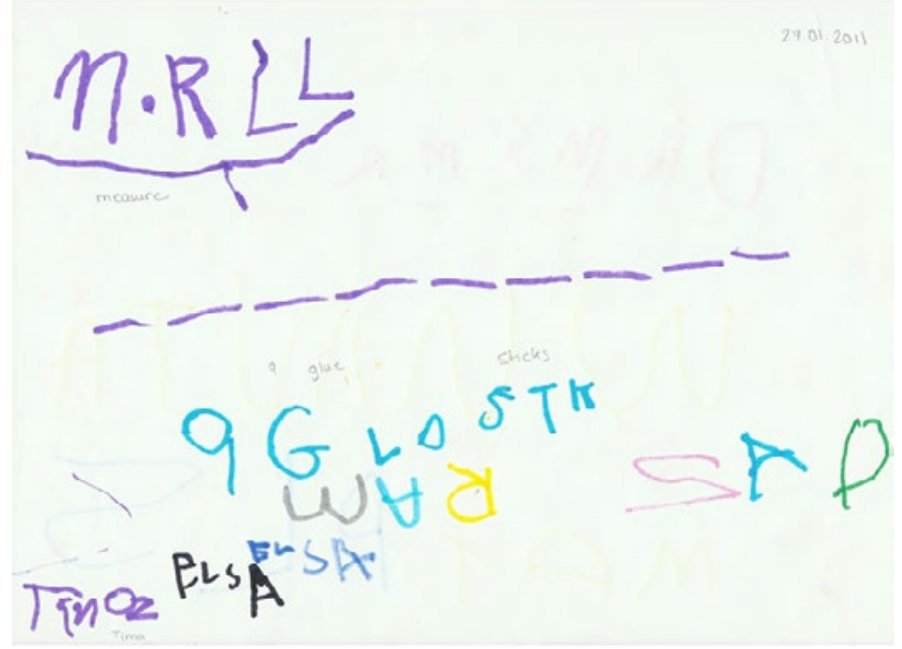

Figure 1: Letter from a group of four-year-old children requesting a new classroom doormat that is nine glue sticks in length.

Figure 1 shows one of several letters written by the children to request a new doormat for their classroom. The creation of the request letters was the culmination of several weeks of measurement activities initiated by the children in "measuring things". The original reference to measuring length was indirectly initiated by teachers when they noticed the children's interest in some measuring tools around the room. The teachers placed a foam metre stick on the wall near the classroom kitchen at a height accessible by the children without calling attention to it. After one day, several students noticed the metre stick and began standing up against it, comparing themselves to its height. One of the students noticed it was just like what his mother did with him at home keeping track of his height on the wall in his bedroom. They began assigning numbers to one another based on where the top of each person's head matched up with the number on the metre stick. Then they began comparing their numbers to one another to see who was taller or shorter. A few of the students knew the word "measurement" and explicitly talked about what they and their peers were doing in terms of measuring. Over the next several days, the teachers added more quantities of other measuring tools to the classroom environment and some students continued their interest in trying to measure things during inquiry time. Throughout this period of time, children were actively using vocabulary related to comparison and measuring. They understood the significance of the numbers on the measuring tool and understood they were measuring length and what could or could not be measured using particular tools. They were also practicing counting and modelling of quantity in a meaningful context. Teachers did not shy away from introducing correct terminology if students needed it to describe their activity. New words were added to 
the word wall as students began using them regularly in their interactions with one another and with the teachers.

A few weeks later, on a rainy morning the classroom doormat had become wet and muddy. During morning meeting the children suggested they should get a new doormat because theirs was messy. The teacher took advantage of this natural conversation and explained to the children that when teachers want something new for the classroom they have to write a letter to the Principal to make a request. The children liked the idea of making a request. The teacher continued the conversation suggesting that in order to make the request they need some details about what they want. The teacher asked how they can figure out what size doormat to request. One of the children shouted out, "We can measure!" The teacher asked what could we use? She said, "We cannot take the metre stick down from the wall, so what else can we use to measure?" A few students said, "We need long things (making an elongating gesture)!"

From there the teacher asked the children to find anything they thought they could use to measure the length and width of doormats. They brought glue sticks, markers, pens, paper clips and one student brought a measuring tape from the dramatic play centre. They clearly understood that they would be concerned with measuring length (evidence of prior learning). The teacher suggested that before working on the doormat they should practice a little using all these tools to measure. They went all around campus measuring whatever they wanted to with whatever tools they wanted. But they were also asked to make drawings of what they measured and to try to record information about the measurements they made.

During these activities, some children realised that the size of the object might determine how many units would be needed. For example, they noticed that because the teacher's shoe was bigger than a child's shoe they would need more paper clips to measure its length. Also many of the children spontaneously compared units and noticed the relationship between the unit size and the measure, an idea usually reserved for older children. For example some noticed, "I need more paper clips than markers because the paper clips are smaller." One boy compared the markers to the measuring tape and recorded numeric measures alongside each equivalent number of markers. The children were invited to share their ideas each day either in morning meeting or in wrap-up time, and any related work was displayed prominently in the classroom.

Eventually the teachers brought the class back to the doormat request and the children suggested they go around the school measuring other doormats as well as their classroom doorways in order to collect data. The children are familiar with collecting data to find answers to questions (Lehrer \& Schauble, 2000). After a couple of days of measuring doormats and doorways the children had the data they needed to prepare their letters. Their request was granted.

Even though the series of activities was highly focused on developing mathematical ideas (specifically measurement), there was also a strong element of literacy 
development integrated because of the vocabulary development happening naturally, asking students to record their findings along the way, and because of the larger context of making the letter of request. In fact, the idea of writing a letter of request was carried over by one of the students in a future unit of inquiry the following year. A small group of children became interested in creating a house (not a cage) for their class pet, a lizard they had named Lizzo. One of the girls decided to write her grandfather a letter asking for his help because he is a carpenter.

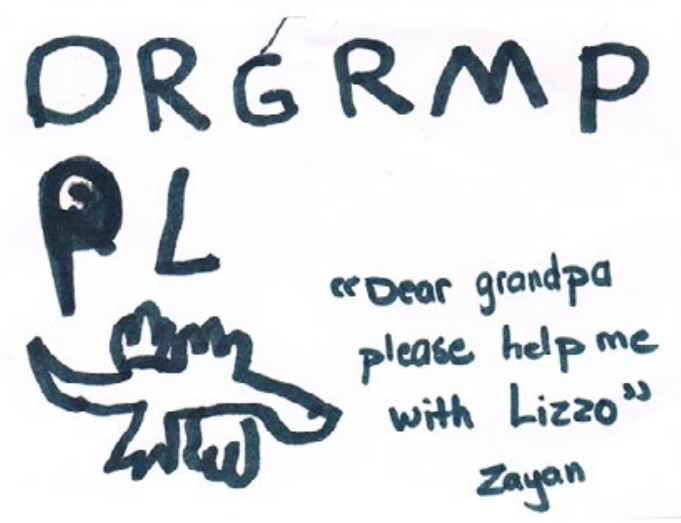

Figure 2: Letter from a five-year-old asking Grandpa to help build a house for the class pet, a lizard named Lizzo.

The letter is shown in Figure 2 with a conventional translation written by the teacher. This letter represented Zayan's first attempt to represent a message as a complete sentence in writing. In the letter, she is demonstrating a typical stepping-stone toward conventional writing by using the beginning letters and other prominent consonant sounds in her message.

\section{Writing and Telling Mathematical Stories}

Five-year-old children draw and write simple subtraction stories. Is this about numeracy or literacy? 


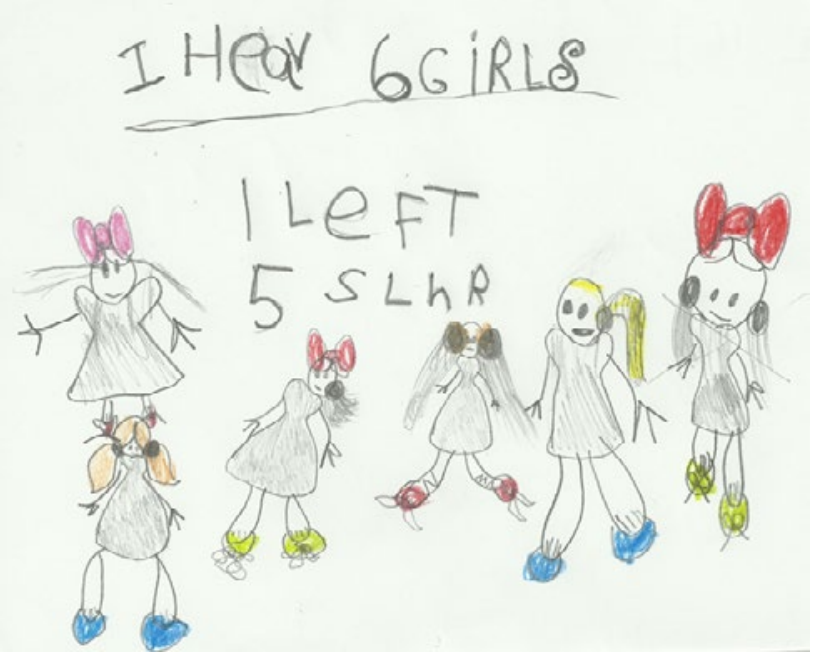

Figure 3: Math story of a five-year-old: "I have 6 girls, 1 left, 5 still here."

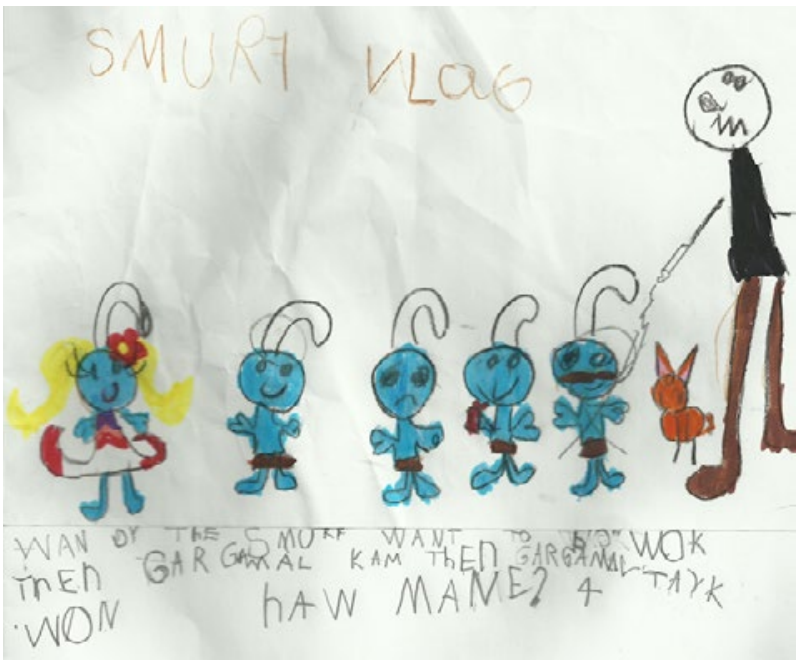

Figure 4: Math story of a five-year-old: "One of the smurf want to go work then Gargamel came the Gargamel took one. How many? 4."

Asking children to create simple arithmetic stories and act them out or draw them is a common early years' activity that affords the opportunity for children to represent their numerical understanding concretely. Commonly children are asked to write the number sentence that goes with the story. However, if children are also asked to write the story with both words and symbols, then it becomes an opportunity to practice 
letters, sounds and words - an opportunity to create a meaningful and mathematically accurate message as a complete sentence.

There is also evidence that younger children naturally infuse numerical concepts they are aware of into creative storytelling and drawing. For example, four-year-old Abdullah drew a picture of a telephone keypad and explained his story, "I can make a telephone with numbers on it. I can call Aunt Hoda. It's zero-one-eight six-one-fivethree-six. I'm going to call and tell her to eat because she is hungry. I will tell her to eat carrots because they are her favourite." In another example, Emily drew a picture of a watch and she proudly announced, "This is a watch the time is 11 and 10!" Finally, Alex drew a picture of a man chasing another man in a game. He described the story in the picture saying, "This picture is of a strong man. The man punched one, two, three, four, five, six, seven, eight, nine, ten walls! He reached and hit the last wall and he found eyes for the bad guy."

Answering questions with data

A class of four-year-old children create a collective tally of their favourite fairy tale characters. Is this about numeracy or literacy?

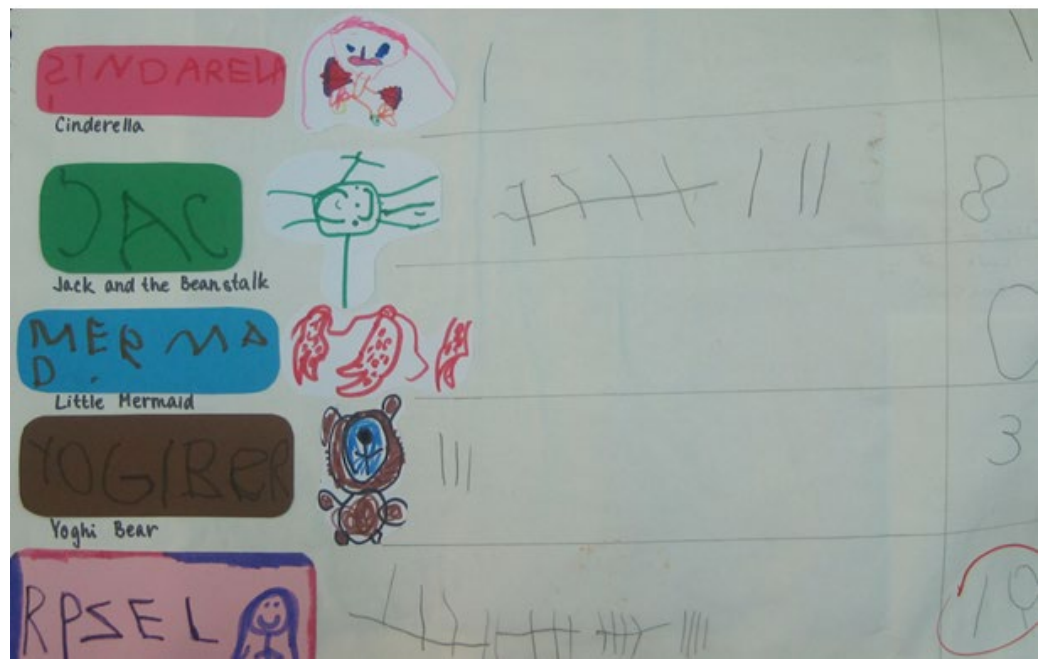

Figure 5: Four-year-olds' tally of their favourite fairy tale characters.

Not only do children naturally engage in making sense of their experiences as data, but they can also engage in purposeful data collection and analysis (Lehrer \& Schauble, 2000) related to their own interests or prompted by things happening in their environment. Thus, the children know at an early age that data are constructed to answer questions. In other words, authentic purposeful data collection is designed by people and aimed at trying to find answers to specific questions that can actually be answered with data. The entire process of conceiving of a question, planning 
what data to collect and how to collect it, deciding with others how to organise it, interpret and analyse or make sense of the data collected offers a rich multitude of opportunities for children to build both numeracy and literacy.

Mathematical representation and work with data can also be brought in to enrich play and dramatic activities (Gronlund, 2010). Many of the typical dramatic themes for children's play are ideal contexts for exploring and interacting with mathematical ideas and relationships. The teacher can naturally infuse questions or prompts that draw attention to math ideas without changing it into an academic lesson. Children can be encouraged to count, use numeric symbols to represent their work, create tallies and so on.

Figure 5 shows an example in which children were engaged in creating all the elements of the frequency tally around the question of which was their favourite fairy tale character. They decided on the categories (characters). They wrote the category labels, they recorded the tally marks and a third column was added for the children to count the tally marks and write the total number. The creation of the tally provided an opportunity to practice sounding out words, writing, collecting data, organising the data, counting and writing numbers. And then of course the children were also engaged in a rich discussion of the tally chart they created and what story the data told and what they could know from the data.

The literacy aspect can be pushed even further. Figures 6 and 7 show survey recording sheets created by two five-year-olds. As part of their unit inquiring into the roles of different people in our community, the children came up with their own question that would help them get to know some adults in the community better. Here the teachers had to facilitate the inquiry by arranging with colleagues and administrators for the children being able to roam around the school asking them questions. The recording sheets include each child's own survey question, the names of the staff members they surveyed and the answers given by those surveyed.

This activity provided an opportunity for the children to interact socially with staff members, generate their own investigatable questions for a purpose, collect data, and spontaneously practice sounding out and writing (possibly novel) words dictated to them by their survey participants. Later when all the surveys were finished they could organise and mathematise their data, which is also a form of "going back to" or editing or reusing information to make something new or to reorganise to see something new. This activity was full of opportunities to practice both literacy and numeracy skills. The children's interest was maintained because they were making sense of questions they generated and that mattered to them! The children's work and practice of skills were contextualised in situations they were interested in and in purposeful activity, rather than focusing all their attention on decontextualised and standardised worksheets. 


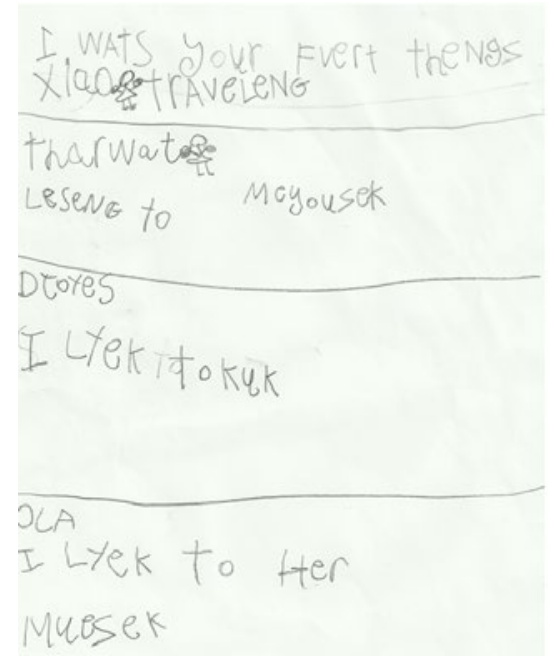

Figure 6: A five-year-old's survey recording sheet asking staff members, "What is your favourite thing?"

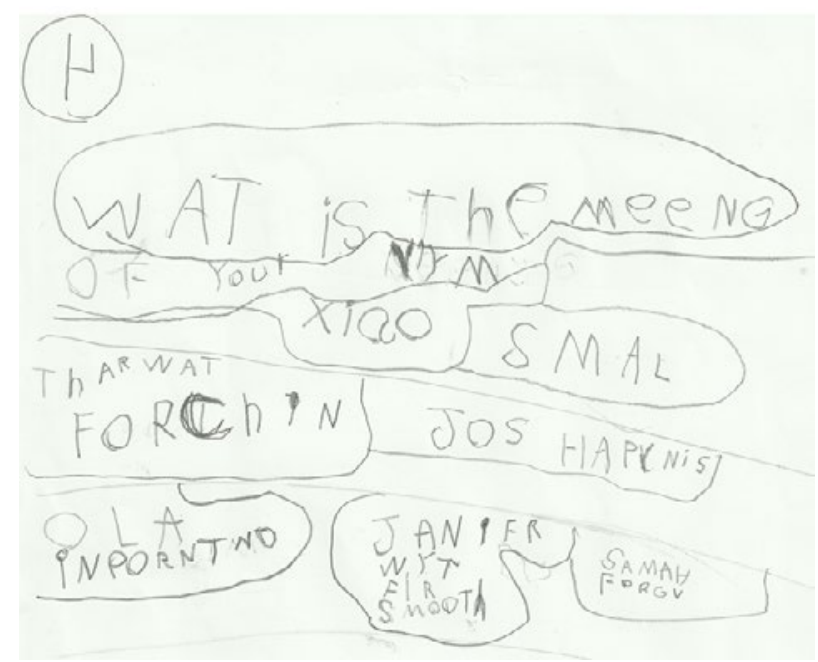

Figure 7: A five-year-old's survey recording sheet asking staff members: "What is the meaning of your name?"

\section{Concluding remarks}

The idea that numeracy and literacy skills can be developed in the context of inquiry might not seem like a new idea. However, when we introduce the notion that such 
activity can and should be built from the interests and ideas of the children, rather than determined a priori by adults or textbooks, the idea becomes more challenging (Castagnetti, Vechhio \& Malaguzzi, 1997; Sobel, 2008; Stacey, 2009). Indeed, Munn (1994) shed light on the fact that very young children bring their own beliefs and goals about reading and number to the learning process that differ from the beliefs and goals of adults. Early years education can help children to understand adult meanings of signs and symbols without imposing those meanings in a directive way.

We must reflect on the role of the learning environment, as well as how curriculum is co-constructed by children and teachers in their interactions in and about the learning environment (Daws, 2005). Even though this approach dictates that children are expected to be more active in leading the learning process, it does not mean that the teachers become less active. The teachers in the examples above had to engage in a tremendous amount of research, planning and collaboration in order to open up the space for the children to inquire and to advance their understanding and skills the ways the teachers hoped for. The role of teachers and other adults is not only as facilitators (as we are fond of saying), but as listeners, observers, documenters and interpreters of children's thinking. A vital aspect of opening up space for children's inquiry is that the teacher's image of herself is fundamentally that of a researcher - an inquirer, a documenter, a learner.

It is not easy for most educators to make this shift in thinking - or to translate that into the creation of a different kind of learning environment in school that opens up new possibilities for what can happen there and for understanding more about it. Teachers must engage in careful planning, discussion with colleagues, and interpretation of data in the form of children's work or records of conversation, and a tremendous amount of observing and listening to the children to maximise the opportunities for learning. At the same time, planning must be flexible in order to allow the child to lead the learning process. The children's point of view often gets lost in our well-intentioned efforts to make sure they will learn "what they are supposed to" (Short, 2009). In these efforts we often do not genuinely try to figure out what they are actually learning and how we can help that natural process grow - as long as we have "covered" or "exposed" children to what they are supposed to learn.

We need to allow ourselves the latitude to ignore our traditional objectives and worksheets and ways of classifying knowledge and instead get closer to how the children experience the world and learn from it and try to bring that into the school-based learning environment. In order to see and hear and make visible what is happening with young children, we have to move away from thinking about mathematics and language learning only within the confines of units or lessons with clearly defined prior objectives as we traditionally think of them. Instead we have to think about the role a child's mathematical and linguistic sense have as the child's natural inquiry processes play out and how new insights and developing understanding can be afforded through the larger process of making sense of their experience. If we can ground the discussion in the actual work of the children then the essential relationship between literacy and numeracy building becomes clearly visible. 


\section{References}

Bruner, J. 1977. The process of education. Cambridge, MA: Harvard University Press.

Bruner, J. 1990. Acts of meaning. Cambridge, MA: Harvard University Press.

Castagnetti, M., Vecchio, V. \& Malaguzzi, L. 1997. Scarpa e metro (Shoe and meter). Reggio Emilia, Italy: Reggio Children.

Daws, J. 2005. Teachers and students as co-learners: Possibilities and problems. Journal of Educational Enquiry, 6(1):110-125.

Dewey, J. 1916. Democracy in education. New York: The Free Press.

Edwards, C. 2002. Three approaches from Europe: Waldorf, Montessori, and Reggio Emilia. Early Childhood Research and Practice, 4(1):2-14.

Erickson, H.L. 2007. Curriculum and instruction for the thinking classroom. Thousand Oaks, CA: Corwin Press.

Gronlund, G. 2010. Developmentally appropriate play: Guiding young children to a higher level. St. Paul, MN: Redleaf Press.

International Baccalaureate Organization. 2009. Making the PYP Happen. Cardiff, Wales: IBO.

Katz, L.G. \& Chard, S.C. 2000. Engaging children's minds: The project approach (2 ${ }^{\text {nd }}$ Edition). Stamford, CT: Ablex Publishing Corporation.

Lehrer, R. \& Schauble, L. 2000. Investigating real data in the classroom: Expanding children's understanding of math and science. New York: Teachers College Press.

Lindfors, J.W. 1999. Children's inquiry: Using language to make sense of the world. New York: Teachers College Press.

Munn, P. 1994. The early development of literacy and numeracy skills. European Early Childhood Education Research Journal, 2(1):5-18.

Nelson, K. 1986. Event knowledge. Hillsdale, NJ: Lawrence Erlbaum.

Prairie, A.P. 2005. Inquiry into math, science and technology for teaching young children. Belmont, CA: Delmar, Cengage Learning.

Reggio Children. 2011. The wonders of learning: The hundred languages of children. Reggio Emilia, Italy: Reggio Children.

Rinaldi, C. 2006. In dialogue with Reggio Emilia: Listening, researching, and learning. New York: Routledge.

Scheinfeld, D., Haigh, K. \& Scheinfeld, S. 2008. We are all explorers: Learning and teaching with Reggio principles in urban settings. New York: Teachers College Press.

Short, K. 2009. Inquiry as a stance on curriculum. In S. Davidson \& S. Carber (Eds.), Taking the PYP forward: The future of the IB primary years programme; 9-26. Glasgow, Scotland: John Catt Educational Ltd. 
Sobel, D. 2008. Childhood and nature: Design principles for educators. Portland, Maine: Stenhouse Publishers.

Stacey, S. 2009. Emergent curriculum in early childhood settings. St. Paul, MN: Red Leaf Press. 